University of Nebraska - Lincoln

DigitalCommons@University of Nebraska - Lincoln

Faculty Publications - Department of

Philosophy

Philosophy, Department of

10-1975

How to Apply the Categorical Imperative

Nelson T. Potter Jr.

University of Nebraska - Lincoln, kjohnson6@unl.edu

Follow this and additional works at: https://digitalcommons.unl.edu/philosfacpub

Part of the Continental Philosophy Commons, and the Ethics and Political Philosophy Commons

Potter, Nelson T. Jr., "How to Apply the Categorical Imperative" (1975). Faculty Publications - Department of Philosophy. 12.

https://digitalcommons.unl.edu/philosfacpub/12

This Article is brought to you for free and open access by the Philosophy, Department of at DigitalCommons@University of Nebraska - Lincoln. It has been accepted for inclusion in Faculty Publications Department of Philosophy by an authorized administrator of DigitalCommons@University of Nebraska - Lincoln. 


\section{HOW TO APPLY THE CATEGORICAL IMPERATIVE}

\section{NELSON POTTER JR.}

"Act only on that maxim that you can at the same time will as a universal law." Many have thought that this formulation of the categorical imperative could not be successfully applied to particular moral situations to determine what kinds of actions are right and mrong. Others have thought that it could be, and have defended Kant against his critics. Much has been written about Kant's famous four examples in the Groundwork of the Metaphysics of Morals (Grundlegung), both to criticize and to defend Kant's sample application arguments. In fact, the application of the categorical imperative is by now a well worn topic.

The aim of the present paper is to give a new positive interpretation of how the categorical imperative is to be applied. There have been critiques of Kant's applications and defenses of Kant against such criticism, but it is surprisingly seldom that a positive interpretation of how the categorical imperative is to be applied has been offered. ${ }^{2}$

The present interpretation is presented by giving an account of the second of Kant's four examples in the Grundlegung ${ }^{3}$ - the argument against making a lying promise. In certain ways this application - a derivation of a perfect duty to others - may serve as a model for other applications, though there are also important ways in which imperfect duties and duties to oneself are different from such a duty. Also, the kind of application set forth here is based on the doctrine of the Grundlegung, with some supplementation from Kant's later ethical works; but it does not take into account, for example, the detailed and quite different account of the application of the categorical imperative in the Metaphysics of Morals. In the context of that work the making of a lying promise would either be a violation of a contractual or property-right related obligation, ${ }^{4}$ and hence fall under the philosophy of right (Recht), or else, as a lie be a 
violation of a duty of virtue. ${ }^{5}$ In either case the categorical imperative would be applied in a different way than it is in the Grundlegung. Nevertheless, the argument from the Grundlegung is of some interest, because it is a good model of a Kantian derivation of a specific moral obligation. Further, the Grundlegung is the work by Kant that most are familiar with; thus in terms of the general debates concerning Kant's ethics, it is perhaps most important to see how the categorical imperative as it is discussed in that work can be successfully applied.

Though the lying promise argument comes from the Grundlegung, other elements of the present interpretation -- for example, the account of the nature of "maxims" - draw significantly upon Kant's later writings on ethics. It is necessary and unavoidable to range more widely in developing an interpretation of the application of the categorical imperative, for it is impossible to give an adequate account of that topic using only the information concerning Kant's views that the Grundlegung gives us.

Further, there are certain elements of the present account that go beyond what Kant himself said, but that are compatible with what Kant does say, and that serve to complete and indeed to make possible a successful application of the categorical imperative; this is particularly true of the discussion of action- and end-description in the last part of the essay.

The claim of this paper is only that the categorical imperative can be successfully applied to particular kinds of action to determine which are right and which are wrong according to that principle. This paper does not claim to show that the categorical imperative is a true or correct moral principle, or that the particular kinds of actions said to be morally right or wrong according to a successfully applied categorical imperative are indeed morally right or wrong as that principle says.

In Section I a criterion of success for the application of the categorical imperative will be proposed and commented upon. In Section II an interpretation of the Kantian conception of a maxim is developed for use in what follows. Section III will set forth the lying-promise argument as it is found in the Grundlegung, make a few comments on it, and propose an interpretation of the alleged "contradiction" that results from the attempt to universalize an immoral maxim. Section IV will take up the criticism that Kant has no way of determining how an action shall be described for the purposes of moral evaluation; if this criticism is correct, then attempts to apply the categorical imperative cannot be successful. I 
shall propose a way of answering the criticism.

\section{I}

A successful application of the categorical imperative consists of an argument having only one moral premise (the categorical imperative), and whatever true factual and causal empirical premises are needed, from which a conclusion concerning the moral rightness or mongness of some particular kind of action follows.

A number of comments on this criterion of successful application are appropriate:

(1) Some interpreters ${ }^{6}$ have thought that Kant thought that the categorical imperative could be applied to derive particular moral conclusions without the use of any empirical propositions at all. This is an incorrect interpretation of Kant. ${ }^{7}$ Empirical premises may be used in the successful derivation of particular moral obligations according to him.

(2) Hegel and others have regarded the categorical imperative, first formulation, as a merely "formal" principle which was inadequate to deduce particular moral conclusions without the use of subsidiary moral premises. ${ }^{8}$ This is perhaps the most common interpretation-cum-criticism of Kant's moral philosophy. It will have been shown false if there is a successful application of the categorical imperative in the sense defined above, since the requirement is that in such a moral argument there be only one moral premise, and no subsidiary or additional moral premises.

(3) The categorical imperative is in the first instance a principle that can be used to determine the rightness or wrongness of an action - that is, to determine what actions are in accord with duty, or not. Thus an action may be in accord with the categorical imperative in the sense that it is right and not wrong, but it may be an action not done from duty, and therefore not a morally good action. A morally good action is a right (i.e., permissible) action that is done because it is right.

\section{II}

The categorical imperative is applied to maxims. Kant tells us that maxims are "subjective principles of action."

"Subjective" for Kant means that which has reference to the subject, belongs to the subject, springs from him, or has its ground in him. ${ }^{10}$ As the term is used in Kant's ethical writings anything is subjective that is dependent upon the empirical nature of the 
experiencing subject, and especially anything having to do with feeling and desire. Thus a subjective principle of action is a principle which springs from the agent's feelings or desires, and which is efficacious only for his own action. In contrast imperatives and laws are said to be objective, and hence are binding, not just upon the agent who adopts or accepts them, but upon any rational agent. ${ }^{11}$

The "subjectivity" of the maxim means, among other things, that its adoption by an agent implies nothing concerning its efficacy or bindingness upon the choice of others or concerning its moral acceptability. Thus some maxims are in accord with objective principles of right and wrong and others are not. Actions that flow from the adoption of a maxim will ordinarily be right or wrong according as the maxim is morally acceptable or not.

Kant tells us that maxims, like other kinds of principles, have a "form" and a "matter." the will."13 This "object of the will" is the end or goal of the action mentioned in the maxim. ${ }^{14}$ Thus maxims include as their "matter" the end of action. Kant tells us in the Metaphysics of Morals that "every maxim contains an end." ${ }^{15}$ The doctrine that maxims have a "matter" and thus mention an end or goal of action is closely related to Kant's often expressed view that all action is for the sake of an end. ${ }^{16}$ Kant is less clear about what the "form" of a maxim is, but fortunately for our purposes it is not necessary to arrive at an answer to this question.

When Kant puts forward examples of maxims, they are usually stated as general policy decisions, which call for the performance of a certain kind of action. For example, Kant speaks of "the maxim of getting out of a difficulty by a false promise." 17 And he states the maxim of suicide as follows: "From self-love I make it mv principle to shorten my life if its continuance threatens more evil than it promises pleasure." ${ }^{18}$ Both of these examples call for the performance of a certain kind of action, and seem to indicate that the action is to be done for the sake of a certain end. The end of action in the first example is that of being out of a difficulty. The phrase "from self-love" in the second example may be taken as a generalized reference to the end of being happy or avoiding pain.

Thus to adopt a maxim is to choose to perform a certain kind of action for the sake of a certain kind of end, and the statement of the maxim should include a description of the action and the end to which the action is a means. ${ }^{19}$

The following comments concerning maxims and Kant's general philosophy of action may be useful: 


\section{APPLYING THE CATEGORICAL IMPERATIVE}

(1) It may be objected to Kant's concept of a maxim that it implies an overintellectualized conception of action, according to which we are implicitly or explicitly following a rule whenever we act. This objection is probably well taken. The idea that to act is to have adopted a maxim of action implies a certain paradigm of action, according to which the action is (a) chosen following deliberation (rather than being merely voluntary), (b) a commission rather than an omission, (c) one for which we are directly rather than indirectly responsible, etc. The conception may, then, by extension, be applied to other kinds of action by reference to this paradigm. But many attempts to thus apply the paradigm to non-paradigmatic examples will, no doubt, run into problems and produce artificialities.

(2) For the purposes of the present essay it need not be insisted that maxims include ends. This insistence becomes necessary only when we move to consider two topics not taken up in this essay: (a) the application of the categorical imperative to derive duties of virtue, and (b) Kant's doctrine of freedom. It is only necessary here to insist that in Kant's view all action is for the sake of an end, for the end of action will have a key role to play in arriving at the proper description of the action for the purposes of moral evaluation.

(3) It may be asked whether Kant held to this understanding of the importance of the end of action in all of his ethical works. For Kant's view that all action, including action from duty, is for the sake of some end, is an unfamiliar doctrine, particularly to persons whose main reading in Kant's moral philosophy has been the Grundlegung. The Grundlegung contains no clear statement for or against the present interpretation of maxims or of the importance of the ends of action. Thus it may be that when Kant wrote the Grundlegung he had not thought through the significance of the role of ends in moral philosophy and in action generally, within the scope of his critical doctrine of ethics. However, there are quite clear discussions of the significance of the ends of action in all three of the later works on moral philosophy written during Kant's critical period: The Critique of Practical Reason, Religion within the Limits of Reason Alone, and Metaphysics of Morals. The present account of the importance of ends of action in relation to maxims is based primarily on those later works. ${ }^{20}$

(4) Still another limitation of the philosophy of action underlying the conception of the maxim is that Kant takes no account of the possibility of an individual adopting competing maxims, con- 
flicting maxims, or maxims which have been adopted with varying degrees of commitment; especially in view of the problems resulting from conflicting maxims, it might be best to understand a "ceteris paribus" clause as attached to adopted maxims. ${ }^{21}$

\section{III}

Let us now turn to the lying-promise example of the application of the categorical imperative. We may restate Kant's famous second example ${ }^{22}$ as follows: Our agent, $\mathrm{A}$, is in financial difficulties, and needs money to stave off financial disaster. He knows he can get the money he needs from his well-to-do friend, B. But he knows that he can get money from $B$ only as an informal loan, i.e., the money will be given $\mathrm{A}$ upon A's promising $\mathrm{B}$ to pay it back at a certain time. He arranges the loan, though he knows perfectly well that he will not be able to repay it in the required time; thus when A promises B to repay the loan, he is promising to do something that he has no intention of doing. He is, in other words, making a lying promise. We may tentatively formulate the maxim of the action as follows: "Make a lying promise in order to get the money you need."

Let us suppose in the discussion that follows that there are no other major facts morally relevant to the case such as the following: the financial disaster that will accrue to $B$ if the loan is not repaid; the bond of friendship that has existed between A and B for years, and which would be violated by A's making a lying promise; the availability of other means of getting the money; the utilitarian or teleological assessment that A ought or ought not to do what he is thinking of; the possibility that A will have to pay much more in the long run for making the lying promise than he would if he didn't, so that his act would be imprudential; the fact that B got his money dishonestly; the fact that the social system in which the two men live is such that it unjustly benefits B and injures A. Any such factors, if they obtained, might be relevant to the judgments that A ought or ought not to make the promise, and more than likely they would be relevant to some of the practical judgments that may surround the proposed action.

Kant tells us in the first formulation that we are to test our proposed maxims by regarding them as "universal laws" or "universal laws of nature." ${ }^{23}$ To do this A will imagine his maxim to be a general psychological law to the effect that whenever someone is in circumstances similar to his and wants to get money he will make a promise to repay, even if he knows that he will not be able to do so. 
'This imagined new psychological law (the cause is the desire to have the money and the effect is the making of the lying promise) is sperimposed upon the world as we know it, and the question is aked: What would be the result if there were such a law?

It should be noted that the "psychological law" we have mentioned is not in fact true. That is, it is not the case that phenever someone finds himself in need of money in circumstances like those of $\mathrm{A}$ he will invariably make a lying promise in order to get it. Moral persons would not do such a thing, for example, and if they, or anyone else, have a will to avoid that action, they are, ordinarily, successful in avoiding it.

If we treat the maxim in this way as a law of nature, we suppose that whenever anyone wants or needs money and can get it by making a lying promise, he does in fact make a lying promise. The result of such a practice would be, we may suppose, that people would come to know the existence of this causal law and would no longer believe or put trust in promises made in such circumstances. And the effect of this would be that a person could no longer gain his end by making a lying promise. If this estimate of the results is correct, then the effect of such a universal law of nature would be that no one would be able to achieve his end of getting money by making a lying promise. If universalizing the maxim has the result that it is impossible to achieve the end mentioned in the maxim by performing the action mentioned in the maxim, then Kant says that there is a "contradiction" and that we "cannot will" the maxim as a universal law. The categorical imperative says that maxims that cannot be willed as universal laws ought not to be acted upon; thus the lying promise maxim ought not to be acted upon.

Kant's statement that maxims which are violations of perfect duties result in a "contradiction" when they are universalized ${ }^{24}$ is one that has caused bewilderment to his interpreters and glee to his critics. Where is the contradiction in our example? It lies between the causal belief that is presupposed by the maxim of making a lying promise, viz., that such action will be efficacious in getting one the money, and the result of that maxim's becoming a universal law of nature, viz., that such an action will not be so efficacious. These two statements contradict one another, and a world in which the maxim is a universal law having the empirical consequences mentioned, and where the maxim's presupposed causal belief is also true is impossible.

The following comments on this example may be made:

(1) It was proposed that we limit our discussion to a limited 
number of morally relevant facts about the example; my way of stating the limitation suggested that moral judgments made on the basis of such facts be regarded as defeasible should other morally relevant facts be presented. Kant seems to think that on the basis of considerations of the kinds we have mentioned he can arrive at a conclusive judgment that making a lying promise is as such wrong, regardless of what other circumstances may obtain. That is, Kant seems not to accept the view that moral judgments are provisional because they may be overturned by additional knowledge. He may have thought that complete or final empirical knowledge, e.g., of the truth of certain laws of nature, or of the morally relevant characteristics of an action, was possible. Or he may have thought that a moral judgment made in the light of all the relevant beliefs possessed by the person who makes the judgment is a true and final moral judgment; that is, his conception of duty may be more "inner" or "subjective" than the view that moral judgments admit of being overturned by additional knowledge.

In his discussions of the application of the categorical imperative Kant does not ordinarily distinguish between the agent's beliefs concerning an action and the facts concerning that action; that is, he does not discuss cases of ignorance of fact, and thus his views concerning the relation between duty and ignorance of fact do not emerge clearly. This is probably because he aims deliberately to consider only cases that are idealized in the respect that ignorance of fact is not an issue. In discussing Kant's ethics it is thus useful to simply suppose that the person making the moral judgment was not lacking any relevant knowledge.

(2) The maxim in the example mentioned a proposed action that was a means to an end also mentioned in the maxim. Thus the maxim presupposes whatever empirical-causal knowledge is necessary to know that the proposed action would be the cause of the end.

(3) The end mentioned in the maxim is never morally evil, in Kant's view, and we can never establish by considering the end of action alone a presumption that an action for the sake of that end is morally wrong. In the tentative statement of A's maxim, the end was described as "having money." Such an end is an intermediate end, i.e., a means to a further end, perhaps the end of A's having his creditors paid, and that is perhaps a means to the end of A's being able to continue to enjoy a life of comfort and the respect of his fellows, and those latter ends A perhaps desires for the sake of his own personal happiness. The last mentioned end is not an inter- 
mediate end. Any intermediate end of action which is not adopted out of moral considerations can be traced back to the desire for one's own happiness, in Kant's view. ${ }^{25}$ One's own happiness as an end of action is not morally pejorative but morally neutral. The means to that end may or may not be narrowly selfish, for example; they may even be altruistic as in the case of a person who helps another because of the satisfaction he would take in that other's happiness. Though such ends are morally neutral, they are all, of course, non-moral goods.

(4) The categorical imperative thus applied is not a utilitarian principle, for two reasons: (a) In no case are we to consider actual consequences of an agent's performing a given action. We are to consider only consequences of the universal adoption of a maxim of action. (b) In the present case we are not concerned with the value-consequences of the universal adoption of a maxim of action, in the way that perhaps a certain kind of rule utilitarian might be. We are concerned only with the results of such a universal adoption of the maxim, with respect to the state of affairs mentioned in the maxim as the end of action. That is, we are concerned with such results in a nonvaluational way - we are only interested in whether certain results will flow from certain hypothetical circumstances, and thus our judgments of such results are in the nature of scientific predictions, rather than utilitarian estimates of value consequences.

Let us now review the application procedure, in a series of steps:

(1) "Make a lying promise in order to get the money you need," is a proposed maxim.

(2) That maxim presupposes (implies) the following causal statement: "By making a lying promise in the proper circumstances, I shall be able to get the money I need."

The maxim in (1) mentioned a proposed end (having needed money) and a proposed means to that end. The statement mentioned in (2) simply says that the action in question is a means to that same end.

(3) If everyone adopted this maxim, the result would be that one would not be able to get the money he needed by making a lying promise (in the same circumstances).

This is an empirical premise, a prediction of what would happen if everyone adopted the maxim mentioned earlier. The empirical evidence for or against (3) can be regarded as part of the argument by which an application of the categorical imperative is made. For 
some maxims, the analogue of (3) may be difficult to arrive at; that is, it is often difficult to estimate what the consequences of the universal adoption of a given maxim may be. Kant was probably not sufficiently aware of such difficulties.

(4) For the maxim mentioned in (1) the presupposed causal statement (mentioned in (2)) and the result of the universal adoption of the maxim (mentioned in (3)) are contradictory.

(5) A maxim whose presupposed causal belief (mentioned in (2)) contradicts the results of its universal adoption (mentioned in (3)) is one that cannot be willed as a universal law.

(4) simply notes a fact about elements of (2) and (3), and (5) is analytic.

(6) One ought to act only on maxims that can be willed as a universal law.

This is the categorical imperative, Kant's moral principle, given as a statement of obligation. ${ }^{26}$

(7) One ought not to adopt the maxim mentioned in (1). (From (1), (4), (5), (6).)

The only moral principle used in this derivation procedure was (6). Thus this procedure and the argument associated with it meet the requirement for a successful application of the categorical imperative set forth in Section I of this paper.

But an assumption of this procedure is that we have available a unique, correct statement of the maxim, and thus a unique, correct description of the proposed action and the end of action. This assumption may not be correct; it must be examined in the next part of this essay.

\section{IV}

There are an unlimited number of possible true descriptions of any action. Since moral evaluation of the action will depend upon the description of the action that is used, we must discover how we are to describe the action, and to evaluate a maxim we must discover both how to describe the action, and how to describe the end mentioned in the maxim. This is a challenge to the example of application of the categorical imperative just put forward, for in order to proceed with the evaluation, we proposed a formulation of the maxim. But we had no reason to think that that formulation was more correct than some other; a different statement of the maxim 
pould have yielded a different result when the Kantian moral test was applied.

Did Kant have an adequate procedure for arriving at the correct formulation of the maxim for the purposes of moral evaluation? Jonathan Harrison expresses serious doubts:

Is it the case that, if an action is wrong, no maxim which would enjoin it can be universalized? Against this there is a very formidable objection, which I am not sure can be answered. It is this: Given any wrong action, you can find a maxim for it which is so specific that it enjoins that action and no other. ${ }^{27}$

W.D. Ross thinks we have here a serious objection to Kant; he states the issue clearly:

Kant's error seems to lie in this: Any individual act is an instance of a class of acts which is a species of a wider class which is a species of a still wider class; we can set no limit to the degrees of specification which may intervene between the summum genus 'act' and the individual act. For example, if C tells a lie to the would-be-murderer, this falls (i) under the sub-species 'lies told to murderous persons', (ii) under the species 'lies', (iii) under the genus 'statements.' Kant pitches, arbitrarily, on the middle one of these three classes, and since acts of this class are generally wrong, and are indeed always prima facie wrong, he says that the particular lie is wrong. ...

We seem, then, to be in an impasse. The test of universalizability applied at one level of abstractness condemns the act; applied at another level of abstractness it justifies it. And since the principle itself does not indicate at what level of abstractness it is to be applied, it does not furnish us with a criterion of the correctness of maxims, and of the rightness of acts that conform to them. ${ }^{28}$

Kant himself seems never to have been aware of this problem. He seems to have assumed that he had readily available a proper description of the action. Indeed, what we may call the problem of "relativity of action-descriptions" is one that has come to the fore only in the twentieth-century. But (1) is there perhaps a solution to this problem implicit in what Kant writes - and clearly enough there that we can call it a "Kantian" solution? Or (2) is there some solution that could be supplied by an interpreter of Kant, that would solve the problem and make possible the application of the categorical imperative? Or (3) is there no solution of any kind forthcoming to the problem that Harrison and Ross propose? If 
there is no solution then any attempt to apply the categorical imperative so as to derive particular ethical conclusions, in the way proposed at the outset, must fail.

I shall show that there may be hints of a solution along the lines of (1) above, but that it does not carry us far enough. I will then propose a solution along the lines of (2); if this solution is successful, an affirmative answer to question (3) will have been avoided.

(1) The following reply might be made on Kant's behalf. Kant emphasizes (especially in the Religion ${ }^{29}$ ) the importance of the spirit as opposed to the letter of the law. Suppose a person makes a lying promise and then justifies that action by reference to the principle: All red haired persons under five feet ten inches and over thirty-five years of age may make lying promises on Tuesday afternoons in May. It might be said that though perhaps a person so acting is obeying the letter of the law, he is clearly not following the spirit of the law. There is somehow a disingenuousness, a lack of sincerity, in any such justification. Hence, the importance to Kant's philosophy and in particular to the application of the categorical imperative of the conception of the "spirit of the law." But there are some difficulties with this line of reply. How do we tell whether a given maxim is contrary to the spirit of the law or not? Unless we answer this question, the decision as to whether or not a given maxim is contrary to the spirit of the law or not is arbitrary. But the concept of the "spirit of the law" was itself introduced to overcome such an arbitrariness in the application of the categorical imperative to maxims. Therefore, to say that our statement of the maxim should accord with the spirit of the law seems to be uninformative.

Let us try a somewhat different direction of attack. We are inclined to say that a person who states his maxim ad hoc in order to justify some action of his is being insincere in the sense that he could not possibly make a lying promise where among his reasons for doing as he did were, for example, that he had red hair, was over thirty-five, and was making the promise on a Tuesday afternoon in May. The spirit of the law requires, it might be said, simply that the reasons mentioned in the maxim be the agent's reasons for acting as he does, or to put it a bit differently, that the description of the action performed be the description under which the agent in fact performs the action. If we know the description under which a person performs an action, we know something of his intentions and motives, and these do not admit of arbitrary change or artificial construction. The reason why the demands of the spirit of the law are violated by some descriptions of an action is that it is clear that 
such self-serving descriptions of the action are not the descriptions under which the agent performs the act. And it is fair that the agent's action be judged according to the description under which he performs the act, for it is, after all, his own description; no account of the action is, as it were, being arbitrarily imposed from without.

(2) But what determines the description under which the agent performs an action? The agent performs the action as a means to some end of his; if we describe the action as a means to that end, we have at least the beginning of a description of the action that is the agent's description. That is, we describe the agent's action as a cause of the achievement of the end. ${ }^{30}$

It might be thought that whatever properties of the proposed action are causally relevant to the achievement of the agent's end are morally relevant properties of that action. But according to such an understanding of "causal relevancy", a great many properties of the action which are obviously not morally relevant properties of the action would be causally relevant. For example, if the promisor approached the promisee about a loan on a Tuesday afternoon in May, and at 4:15 p.m. the promisee asked the promisor whether he promised to repay the money, then the fact that the promisor made his promise at $4: 15$ p.m. on a Tuesday afternoon in May would be a morally relevant property of the action. The promisor must make the promise (we may suppose) when he is asked to do so if he is to get the money. In general, a great many characteristics of the action that intuitively are morally irrelevant - in particular the time and place of the action - will be said to be morally relevant features of the action according to this criterion. Indeed, an action described according to this criterion would no longer be a general description of a kind of action, and thus would not be a suitable description to be included in a maxim of action.

The causal relevancy criterion we are interested in must thus be a criterion of generalized causal relevancy, a criterion that will yield us, not a particular-action description, but a description of a general kind of action. Thus the only properties of the action that will be mentioned are those that are causally relevant in a law-like statement of the kind that the maxim is.

The law-like statement which states a causal connection between the action and its end will be one in which characteristics of the action are mentioned which make it a causally sufficient condition for the end, not properties which make it a necessary condition. If there are any alternative means of realizing a given 
end (and there almost always are) then very few, and perhaps no properties of the proposed action will be necessary conditions. Further, intuitively, when a person has a certain end, he is interested in courses of action that will result in the achievement of his end, i.e., that will be sufficient to bring it about.

It might be objected here that if the proposed action is being described as a causally sufficient condition for the achievement of the end, then since there are almost always a large number of alternative means to a given end, a statement of sufficient conditions for the achievement of a given end would consist of a long disjunctive list of rather particular kinds of actions, each of which is a sufficient condition for the achievement of the end of action. Since the Kantian maxim only mentions one proposed kind of action, we cannot yet have an account of the description of actions that is adequate for formulating such a maxim. But, in reply, it must be recalled that in attempting to formulate a Kantian maxim, we begin our moral deliberation by thinking about an individual action. We are thus seeking a description of it. Thus there could not be a disjunctive list mentioning other actions as well.

We shall thus describe our proposed action as a means to the agent's end, in the following way: Its description will be the one that occurs in a true law-like statement that describes the action by mentioning those properties that make it a causally sufficient condition for the end. In the place of "true" some may want to write "well-confirmed" or perhaps "as well-confirmed as possible, under the circumstances." The thought would be that frequently we must act with less than ideal knowledge of the nature and circumstances of our action; since this is the case, "true" or "well-confirmed" may seem too strong, since frequently our beliefs concerning the proposed action and its consequences are neither true nor well-confirmed. I prefer "true", however, so that we may say, when presented with better factual evidence that causes us to change our mind, that our earlier judgment was incorrect. However, it is worthwhile to take explicit note of the fact that our circumstances of moral deliberation, choice and action commonly are epistemically less than ideal.

We need only add the following requirement, for the preliminary description of the action: that the law-like statement from which we take our description of the action be as general a statement as possible. If we suppose that we have the most general statement of the law we are interested in, then, unless we added 
this proviso, we could arbitrarily add mentions of other properties of the action to its description. The resulting statement would still be a lawlike statement, and the action mentioned in it would still have been properly described.

The criteria of moral relevancy thus far put forward are adequate to exclude from its description a great many intuitively irrelevant properties of the action, and they are adequate to bring about the inclusion of many of the intuitively relevant properties of the action, e.g., (probably) the fact that the proposed action is one of promising.

Now let us imagine that everyone, whenever he might gain something by a promise (i.e., whenever making a promise seems the best and perhaps most convenient way of gaining some personal end) does so. We are now imagining an indefinitely large number of promises being used (over a period of time) to obtain an equal number of personal ends. As we examine this large class of promises, we find that the class of promise-making actions may be divided into sub-classes that have significantly different consequences with respect to the agent's promise-making ends. Promises which are broken (i.e., are not performed, and there is no mutual agreement or understanding about their nonperformance) have different consequences with respect to those ends than those that are not broken. ${ }^{31}$ In general, the keeping of promises tends to result in the achievement of the promisor's ends in promising, and the breaking of promises tends to frustrate those ends. This is because past experience with broken promises tends to make would-be promisees wary of accepting and acting on the basis of new promises. Thus, in general, the keeping of promises is among the set of conditions that are jointly sufficient conditions for the achievement of all the ends for the sake of which the promisors made their promises. Since we tend to describe actions which are universalized in terms of those of their properties in virtue of which they will fail to achieve their ends, we may, in keeping with our causal criterion for describing actions, describe the promise as a promise broken. Thus the breaking of promises causes the non-achievement of promisor's ends, and we may conclude that according to the categorical imperative it is wrong to break a promise.

But we may conclude more than this. We may conclude that it is wrong to do that which results in the breaking of a promise, providing we are responsible for that result. For example, if $\mathrm{A}$ has promised to lend a book to $\mathrm{B}$, but before $\mathrm{B}$ arrives $\mathrm{A}$ lends the 
book to $\mathrm{C}$, A has done that which causes the breaking of a promise; or if someone decides to visit the seashore on a day he has promised to help a friend move, we might say that the decision resulted in the breaking of the promise. Now in the case of a lying promise (i.e., one which the promisor knows he will not keep) the making of the promise is what results in the breaking of the promise. That is, it is not some later decision, action, or circumstance that results in a broken promise, but the very making of the promise itself, since the promisor never intends to keep it. This is perhaps clearest in the case that Kant describes in his example: the promisor there knows that he cannot keep the promise. Thus if it is wrong to break a promise, it is also wrong to make a lying promise.

We have now shown how the description "lying promise" may be attached to the action in our example. This is the description we were after - the one that seems, intuitively, the proper description for moral evaluation, and the one that may be used to show our proposed action to be wrong, along with any other action fitting the general description.

In describing the end as it is mentioned in the maxim, there are two issues: (a) There is typically a series or chain of events that are "ends", with all but the last being intermediate ends, i.e., ends that are also means. Which member of this chain is to be mentioned? (b) Whichever of the "ends" along the chain we choose, it may be described with greater or lesser generality. What is the proper degree of generality for its description? For both of these issues it will be possible only to give general suggestions for describing the end of action, suggestions that will probably be adequate to take care of most but not all cases.

Consider the following series of "ends", from the lying promise example: (i) having the money (from the promise), (ii) paying one's creditors, (iii) being free from harassment and trouble, being able to retain possession of one's belongings, and being able to retain the respect of one's neighbors, both for oneself and one's family, (iv) continuing to be happy. In this instance, it makes little difference which of these intermediate ends we choose. Making a lying promise is equally the cause of all of them. There may be other cases where choosing one member rather than another makes a great difference; it is difficult to know how to anticipate such cases. But it is useful to be aware of the different members of the causal chain, so that one can be aware of what difference such a choice of one member over 
nother might make. It is likely to be more convenient to choose wi end more immediate to the action, since the causal connections htween it and the proposed action will be less complex and thus kss difficult to deal with. And finally, when we choose an intermediate end for mention in a maxim, we should be careful to describe it as a means to the further ends.

(b) If the end of action is described in too narrow a way, instances of the "universal law of nature" that are thereby pecified would be rare, and the effect of such a law might be regligible. Thus it might be possible to will certain maxims as a universal law of nature whose actions are clearly wrong. An example might be the following: "Make a lying promise, to the end of getting exactly $\$ 1,537.36 . "$

We must consider how to describe, not intermediate ends, but more basic ends of action. Often intermediate ends are more readily described than more basic ends. And the description of intermediate ends is dependent upon the description of more basic ends.

Kant, when he thinks of actions based on desire, is thinking of the common, psychologically based and physiologically based motives or ends of action: ends like the having of food, drink, shelter, friendship, sexual expression, and freedom from physical pain: these are all motives or ends that are based in and determined by our empirical-subjective natures. The fulfillment of (for example) the desire for freedom from physical pain, may be said to be a part of happiness, and thus something desired for its own sake. In understanding the nature of such ends and arriving at an accurate description of them we need to make use of our knowledge of what Kant called "anthropology" --- the empirical science of man.

In arriving at an anthropologically based description of the ends of action, we should follow the general scientific canon of attempting to state the descriptions of such ends in as general and theoretically powerful a way as possible. This point is similar to the point made in the previous section concerning the causal criterion of moral relevancy: Just as the law-like statement that includes the description of the proposed action should be as general a statement as possible, so should the description of the end be as general as is consistent with accurate theoretical description. Thus, if alternative descriptions of an end of action were 'eating chicken' and 'eating food,' the latter description should be chosen. 
Kant, in determining the end or goal of action, frequently seems to be using a common-sense psychology of the kind just described. We commonly use a similar kind of "psychological theory," if it may be called that, in describing people's goals, determining their motives, and judging their actions. It is always possible that this "theory." like any empirical theory, may be overturned, in part or in whole, by a new, better-grounded theory. But even apart from such a possibility, there will be cases, psychologically complicated cases, that it will be difficult to deal with: cases of ambiguous motivation, of sadism and masochism, of compulsive acts, the case of a person who kills out of an aesthetic motive ("Her hair was an offense to humanity"), etc. The procedure for arriving at descriptions of the end of action using common-sense psychology will not take care of these cases. Thus the Kantian procedure for arriving at a description of the end of action gives perhaps a reasonable approximation to the correct description for many, but not for all cases.

There might seem to be serious problems in principle with the generally causal-scientific descriptions of actions and of ends that has been proposed. It might be said that the state of our empirical knowledge of the world notoriously changes and advances, and concomitantly so will our descriptions of actions and ends. But this is a virtue, not a defect of the present account. We may never have a final, absolutely correct account of action and of motiva. tion - and our descriptions of both may be expected to change with changes in our empirical beliefs. This is one of several ways in which the formulation of the maxim will be tentative and defeasible; but all of these elements of uncertainty come from the causal-factual knowledge that relates to the proposed action and end. Our general theories and beliefs concerning law-like connections may change. Our knowledge of actions, and their consequences, especially, perhaps, those only proposed, is commonly incomplete. Sometimes there are difficult-to-deal-with borderline cases. There are complexities resulting from pluralities of ends, incompatibilities between the means to different ends (e.g., smoking may be a means to the end of present enjoyment or absence of nervousness, but it tends to be incompatible with the goal of a long, healthy life) and seemingly conflicting bases for moral obligations. The requirement for a "single correct description for the purpose of moral evaluation" that we stated at the outset does not, of course, imply that our proposed correct description may never be revised. These complexities mean that, 
even if the basic principle of morality has no indefiniteness or uncertainty about it, our applications of it must be tentative, gaarded and careful.

To say all of this might seem to be leaving behind the Kantian spirit of moral absolutism. But most of Kant's absolutistic perorations have to do with the certainty, etc. of the basic principle of morality, not its application. He takes note of the fact that empirical knowledge is required for the application of the principle. ${ }^{32}$ And in the second half of the Metaphysics of Morals, which is concerned with the application of the moral law, he recognizes this most explicitly with his regular inclusion of "casuistical questions", which he indicates have uncertain issues, and to which, he thinks, no final answers can perhaps be given. ${ }^{33}$ But after this has been said, it must be admitted that Kant had greater certainty about how actions are to be described for moral evaluation, and that he was less alive to the uncertainty-inducing factors that cause the author of this paper to be more tentative.

Harrison's worry and Ross' objection have now been answered. The excessive specificity of the maxim that Harrison was concerned about is answered by generality requirements that the action description not be an individual action description and that the law-like causal statement connecting means and end be as general as possible. Ross' objection that "the principle itself (i.e., the categorical imperative) does not indicate at what level of abstractness it is to be applied," has been answered by specifying a method for arriving at a proper description, at the proper level of abstraction.

This procedure can scarcely be said to be implicit in Kant, especially since Kant seemed unaware of the problems which it is intended to solve. The only elements of this found in Kant are: the doctrine that the maxim includes an end, discussed earlier, and the concept of the "spirit of the law", as it was discussed in this section, above. Thus the proposals for formulating the maxim cannot be described as "Kantian," and the procedure outlined here is a solution of type (2), mentioned earlier in this section. If it is indeed a successful solution as I have claimed, then we have avoided the conclusion that attempts to apply the categorical imperative must fail. ${ }^{34}$ 
NELSON POTTER, JR.

\section{NOTES}

1 For statements of this so called "first formulation" of the categorical imperative see G, IV, 402, 422; $K d p V, V, 30$. In this essay I shall not distinguish between versions of the first formulation which simply mention "universal law" and those which mention "universal laws of nature." (For the latter formulation see G, IV, 421, 436.) I accept the view of L.W. Beck (put forth in his A Commentary on Kant's Critique of Practical Reason (Chicago: The University of Chicago Press, 1960), pp. 154ff.) and Paul Dietrichson (put forth in his "When is a Maxim Fully Universalizable?" Kant-Studien, Band 55, Heft 2 (1964), pp. 143-170) that the first formulation may only be applied by regarding the universalized maxim as a law of nature. Note: The references to Kant's works are given in abbreviated form. The page references are to the volume and page in Kants Gesammelte Schriften. 22 volumes (Berlin: Königlich Preussischen Akademie der Wissenschaften, 1902-42). Most English translations, including all but one of those below, include the Akademie pagination in the margins. The abbreviations for works by Kant that are cited, together with the English translation of the work used are:

G-Grundlegung zur Metaphysik der Sitten, 1785.

Groundwork of the Metaphysics of Morals, trans. by H.J. Paton (London: Hutchinson \& Co., Ltd., 1956, third edition)

KdpV-Kritik der praktischen Vernunft, 1788.

Critique of Practical Reason, trans. by Lewis White Beck (Indianapolis: The Bobbs-Merrill Company, Inc., 1956).

$R$ - Religion innerhalb der Grenzen der blossen Vernunft, 1793. Religion within the Limits of Reason Alone, trans. by Theodore M. Greene and Hoyt H. Hudson. (New York: Harper \& Brothers, 1960) (This translation does not include the Akademie pagination. References for this work will include two page references, the first the Akademie edition page, the second the Greene-Hudson edition page).

MdS - Metaphysik der Sitten, 1797. The first half translated as The Metaphysical Elements of Justice by John Ladd (Indianapolis: BobbsMerrill, 1965). The second half translated as The Doctrine of Virtue by Mary Gregor (New York: Harper and Row, 1964).

2 A notable exception to this is H.J. Paton's The Categorical Imperative. (London: Hutchinson \& Co., fourth edition, 1963). I have criticized his interpretation in "Paton on the Application of the Categorical Imperative," Kant-Studien, Band 64, Heft 3 (1973), pp.411-422. Briefly, I argue there as follows: Paton thinks that when a maxim is universalized in accord with the first formulation for the purpose of moral testing, it is to be regarded as a teleological law of nature, and it is tested by seeing how the proposed law fits in with nature regarded as a teleological systematic harmony of ends or purposes. But (1) if Paton's interpretation is correct, then the categorical imperative, first formulation, cannot be successfully applied, since nature is not a teleological system and there are no true teleological laws of nature. 
And (2) Paton's interpretation is not in fact correct, Kant never says that maxims are to be regarded as teleological laws when being tested morally, and there is no textual evidence for believing that he thought so. Paton's interpretation is the result of (what I argue are) his incorrect accounts of "maxim", and of the relation between the different versions of the first formulation. A survey of recent literature on the application of the categorical imperative is to be found in M.J. Scott-Taggart, "Recent Work on the Philosophy of Kant" (American Philosophical Quarterly, Volume 3, Number 3 (July, 1966), pp. 171-209).

${ }^{3} \mathrm{G}, \mathrm{IV}, 422$.

${ }^{4}$ Kant's account of property (which includes contracts) begins at $M d S$, VI, 245.

${ }^{5}$ Somewhat surprisingly Kant regards lying, not as a violation of a duty to another, but as a violation of a duty to oneself. MdS, VI, 238, $428 \mathrm{ff}$.

${ }^{6}$ For example, see A.C. Ewing, "The Paradoxes of Kant's Ethics," (Philosophy, XII, 1933, pp. 40-56), p. 49.

${ }^{7}$ For example, see $G$, IV, 412; MdS, VI, 217.

${ }^{8}$ For versions of this charge, see G.W.F. Hegel, The Philosophy of Right, translated by T.M. Knox (London: Oxford University Press, 1952), pp. 90, 254. F.H. Bradley, Ethical Studies (Selected Essays) (New York: The Library of Liberal Arts Press, 1951 (originally published 1876)), p. 94. Hastings Rashdall, The Theory of Good and Evil, two volumes (London: Oxford at the Clarendon Press, 1907), Volume I, p. 110-111. C. D. Broad, Five Types of Ethical Theory (London: Routledge and Kegan Paul, Ltd., 1930), p. 128.

${ }^{9}$ See $G, I V, 400 \mathrm{n}, 421 \mathrm{n} ; K d p V, \mathrm{~V}, 18-19 ; M d S, \mathrm{VI}, 225$.

${ }^{10}$ See Rudolf Eisler, Kant-Lexikon (Hildesheim: Georg Olms Verlagsbuchhandlung, 190), pp. 515-6.

11. See $G, 413,421 \mathrm{n} ; K d p V, V, 18-21$.

${ }^{12} \mathrm{KdpV}, \mathrm{V}, 26-27$.

${ }^{13} \mathrm{KdpV}, \mathrm{V}, 26-27$.

14 See MdS, VI, 384, for a definition of "end" as "an object of free choice."

15 MdS, VI, 396.

${ }^{16}$ For statements of this doctrine see $M d S, V I, 385$; also $R, V I, 6-8 \mathrm{n}=\mathrm{pp}$. 5-7n. For extensive discussion by Kant of his view that all action, including action from duty, is action for the sake of an end, see, in addition to the references above, the Introduction to the second half of MdS and Chapter II of $K d p V$.

${ }^{17} \mathrm{G}, \mathrm{IV}, 402$.

18 G, IV, 422.

19 What is distinctive about this account of maxims is the claim that they include a statement of the end for the sake of which the proposed $k$ ind of action will be performed. Though this point has clear textual support, it has seldom been noted.

20 See the references in note 16 , above.

21 This proposal has no basis in the Kantian text. In fact, it is clear that Kant 
NELSON POTTER, JR.

did not think of maxims as having ceteris paribus clauses attached to them. This point is proposed here only because of the difficulties from which it frees Kant's philosophy of action.

$22 G, I V, 422$.

23 See note 1.

24 G, IV, 424.

25 See $K d p \dot{V}, \mathrm{~V}, 21,22$.

${ }^{26}$ See $G$, IV, 413, where Kant says, "All imperatives are expressed by an ought."

27 "Kant's Examples of the First Formulation of the Categorical Imperative" (Philosophical Quarterly, 7 (1957), 50-62), p. 60

${ }^{28}$ Kant's Ethical Theiory (London: Oxford University Press, 1954), pp. 32-33.

${ }^{29}$ See $R$, VI, $30=$ pp.25-26, and $R$, Book 1, passim.

${ }^{30}$ David Lyons, in Forms and Limits of Utilitarianism (London: Oxford University Press, 1965), p. 57, comes to an analogous conclusion for utilitarianism: "Therefore, the only legitimate candidates for inclusion in the description of an action for the application of a form of utilitarian generalization are causal or consequentially significant properties, that is .... causal properties in virtue of which the universal performances of acts of that kind would produce some utility or disutility."

31 The fine points concerning what promises are broken and what are not need not detain us here. We can confine our attention to clear cases of promises broken and promises not broken, if we choose.

32 See the references in note 7.

33 For example, see $M d S$, VI, 423-4, 426, 428, and passim, to 458.

$34 \mathrm{I}$ wish to acknowledge the readings and helpful comments given earlier versions of this paper by Stephen Barker, Maurice Mandlebaum, Phillip Scribner, Robert Dewey, and John Diehl. 